\title{
Susceptibility of vegetatively propagated Khaya anthoteca to Arbuscular Mycorrhizae Fungi (AMF) soil inoculum infection
}

\author{
Philip Worlanyo Dugbley ${ }^{1,}$, , Irdika Mansur ${ }^{1,2}$, Basuki Wasis ${ }^{1}$ \\ ${ }^{1}$ Department of Silviculture, Faculty of Forestry, Bogor Agricultural University, Dramaga Campus -Bogor 16680, Indonesia \\ ${ }^{2}$ SEMEO Biotrop, Jalan Raya Tajur, Bogor 16134, Indonesia
}

Email address:

philidug87@yahoo.com (P. W. Dugbley),irdikam@gmail.com (I. Mansur)

\section{To cite this article:}

Philip Worlanyo Dugbley, Irdika Mansur, Basuki Wasis. Susceptibility of Vegetatively Propagated Khaya anthoteca to Arbuscular Mycorrhizae Fungi (AMF) Soil Inoculum Infection. Science Research. Vol. 3, No. 1, 2015, pp. 13-18. doi: 10.11648/j.sr.20150301.13

\begin{abstract}
Stem tip cuttings of Khaya anthoteca seedlings were experimented for the trapping of Arbuscular Mycorrhizae Fungi (AMF). This study aimed to determine the effect of hormone and wounding treatments on the vegetative propagation of $K$. anthoteca seedlings and the susceptibility of these cuttings to AMF soil inoculums infection compared to some other bait species such as Sorghum bicolor and Puereria javanica. The results indicated that, K. anthoteca can successfully be propagated through stem cutting with only wounding and without hormone (auxin) applications. Analysis of variance tested at $5 \%$ significance level revealed no differences between the treatment means of hormone and wounding on the number of roots. Again, the lengths of the longest roots were not significantly different over the control treatment. In the trapping experiment, there were no significant differences in terms of root segment colonization between $K$. anthoteca cuttings and the other trapping species. This observation was however, frequent in the young and meristematic segments of the roots for $K$. anthoteca. An average root colonization of $32 \%$ was observed for $K$. anthoteca and the highest recorded by $S$. bicolor of $43 \%$. Thus, about a third of root segments of $K$. anthoteca were colonized by AMF. There was also a significant positive correlation between percentage root segment colonization and the number of counted spores. The study concludes that wounding of $K$. anthoteca six-month old seedlings prior to vegetative propagation by cutting play vital role with respect to the rooting ability of the propagules compared to non-wounded propagules and also not significantly different from that of synthetic hormone application. Again, $K$. anthoteca is susceptible to AMF just like most tropical plant species in Indonesia. Finally, AMF soil inoculums can also be a good source of inoculants for establishing K. anthoteca in areas of degraded lands for revegetation purposes.
\end{abstract}

Keywords: Khaya anthoteca, Vegetative propagation, Hormone, Wounding, AMF soil inoculums

\section{Introduction}

Khaya anthoteca commonly referred to as the African red mahogany belong to the family Meliaceae. This species is heavily exploited, particularly in the East and West of Africa. Again, in places where parent trees are scarce, regeneration is poor and serious genetic erosion is believed to have occurred due to selective felling, habitat loss and degradation. The species is used in high-class cabinet work and for production of veneers and any application where good quality, medium weight hardwood is needed [14]. It also weathers well and is resistant to borers and termites. The dense crown makes it suitable as a shade tree and also popular for windbreaks and as an ornamental plant. It has been successfully introduced in South Africa, Cuba and
Puerto Rico and also, on a limited scale in Indonesia and the Peninsular of Malaysia where it has been used in plantations and Taungya systems. Although seeds are the most common way of natural plant regeneration, vegetative propagation methods/techniques however, offer several advantages. Furthermore, individuals may be recognized within populations that produce a higher quality of the desired product(s) or services. Reports also indicate that vegetative propagation using leafy stem cuttings has been successful in African mahoganies. It would therefore be advantageous to propagate these individuals vegetatively to 'capture' the genetic variation expressed, which may otherwise get lost or diluted during sexual propagation. Cuttings are severed plant pieces with at least one node. Various plant organs can be used for cuttings: stem, root or leaf cuttings. Thus, the concept of vegetative propagation is 
that an exact copy of the genome of a mother plant is made and continued in new individuals. Tropical fruit species have been subjected to vegetative propagation in a number of cases that have found a lucrative export market, e.g. citrus, mango, avocado, and macadamia nut. Tropical timber species have also been cloned, mainly for plantations where uniform trees are needed [16].

It has been widely known that mycorrhizal fungi are capable of improving soil properties, and increasing plant access to relatively immobile mineral nutrients [10]. Other studies have also suggested that, mycorrhiza fungi are the main pathway through which most plants obtain mineral nutrients and as such, are critical in terrestrial ecosystem functioning [20]. Mycorrhizal fungi have over the years played critical roles in nutrient cycling and ecosystem function. In this mutualistic symbiosis, plants exchange photosynthates, not only for mineral nutrients, but also for increased resistance to disease, drought and extreme temperatures. Thus, plants are able to withstand harsh environmental conditions through fungi-plant symbiosis. Generally, mycorrhizal fungi are removed entirely in newly graded lands and always requires inoculation if the objective is a functional terrestrial ecosystem. It is however difficult in getting pure viable spores of Arbuscular Mycorrhiza Fungi (AMF) for effective inoculation. This study therefore examines the susceptibility of Khaya anthoteca cuttings to AMF infections using soil inoculums.

\section{Materials and Methods}

This research was conducted in the glasshouse of the Silviculture Department, Forestry Faculty of the Bogor Agricultural University (IPB).

Materials: Materials used for this study included record log sheets, clip board, pencil, soil sample under Khaya anthoteca plantation forest located at Carita in the forest Banten province of Indonesia, Puereria javanica and Sorghum bicolor, culture pots, plastic rubber, sieves, zeolit, lab coat, gloves, microscope mounting glasses, Rootone $\mathrm{F}$ hormone, $10 \%$ potassium hydroxide $(\mathrm{KOH}), 3 \%$ Hydrogen peroxide, $1 \%$ Hydrochloric acid $(\mathrm{HCl})$, heating plate, wash bottle and trypan blue dye

Tools: Minitab Version 16, Microsoft excel, density gradient centrifuge machine, glass slides, fine and rough forceps, dissecting and compound microscopes.

Cutting Experiment: Cutting of six months old Khaya anthoteca seedlings was carried out at sunlight greenhouse with natural light and at temperatures between 25 and $32^{\circ} \mathrm{C}$ and relative humidity of between $65-80 \%$. The media was sterilized, low in fertility, well-drained but able to retain enough moisture. A piece of stem, about 5 inches long was removed from each seedling with about three sets of leaves on the cutting. The cuttings were then trimmed in the following way:

a. A cut at the bottom of the stem just below a node

(Where the leaf and the bud joins the stem) was made

b. About $1 / 2$ to $2 / 3$ of the leaves removed, starting from the bottom of the cutting. Large leaves were cut into half.

The lower inch of the cutting were dipped in rooting hormone, Root tone F and placed in open space for about 3 minutes for hormone absorption. Holes for each cutting were made using a cleaned rod and cuttings placed in the holes and rooting mix around it gently firmed. Treatments administered were $\mathrm{T}_{1}$ (No wounding, no hormone; $\mathrm{H}^{-} \mathrm{W}^{-}$), $\mathrm{T}_{2}$ (hormone without wounding; $\mathrm{H}^{+} \mathrm{W}^{-}$), $\mathrm{T}_{3}$ (wounding without hormone; $\mathrm{H}^{-} \mathrm{W}^{+}$), and $\mathrm{T}_{4}$ (hormone with wounding; $\mathrm{H}^{+} \mathrm{W}^{+}$). The cuttings were covered with plastic rubbers and placed in an enclosure ensuring high temperature and humidity for stem rooting; a place of warm, bright spot but out of direct sunlight. The rooting mix was checked every few days to make sure it was moist, and watered as and when necessary.

AMF Trapping Experiment: Soil samples were collected from the rhizosphere of Khaya anthoteca plantation site located at Carita, Banten province of Indonesia for the trapping experiment. Ten (10) trees were randomly sampled for soil collection. Pueraria javanica, Khaya anthoteca and Sorghum bicolour were grown in $600 \mathrm{ml}$ culture trays in a planting media consisting of a 2:1 mixture of zeolit and sample soil $(50 \mathrm{~g})$ in the glasshouse. Each soil sample was used in growing all the three species giving a total of 30 sub-samples. $P$. javanica seeds were cleansed using parazone for about 10 minutes and further subjected to warm water treatment for 30 minutes and then germinated on a growing medium (zeolit) for a week. The plant species for the trapping were watered each day over the course of the trapping period for three months. Watering was reduced after the trapping period for the plants to dry and subsequently analysis of the planting media and plant roots. Soil samples from the pot cultures were passed through a 2$\mathrm{mm}$ sieve and $50 \mathrm{~g}$ soil sample transferred to a beaker. Soil aggregates were then crushed with a spatula. Distilled or de-ionized water added to obtain a 1-L suspension and agitated manually for about 15 minutes. The purpose of these steps was to disperse soil aggregates and release AMF spores. The soil suspension was then passed through a stack of sieves of $425 \mu \mathrm{m}, 125 \mu \mathrm{m}$, and $45 \mu \mathrm{m}$ with the finest sieve being at the bottom of the stack. A stream of tap water added to facilitate the movement of spores. The material that remained in the 45 and $125 \mu \mathrm{m}$ aperture sieves were suspended in water and transferred to centrifuge tubes with $60 \% \mathrm{w} / \mathrm{v}$ sucrose and centrifuged for 3 minutes at $2500 \mathrm{rpm}$ separating spore sediments at the bottom of the tube, while organic materials remained in suspension. Spores were isolated and collected under a dissecting microscope, and number of spores associated with each plant species counted. Roots were washed and cleared using $10 \% \mathrm{KOH}$ heated to a temperature of $60^{\circ} \mathrm{C}$ for 22 hours and stained using trypan blue in $1 \% \mathrm{HCl}$ to bind the fungi structures. Roots were prepared on glass slides and segment colonization was determined by the visual estimation method. Ten (10) roots were prepared on each glass slide representing a sample and each root observed at $40 \mathrm{x}$ 
magnification with 10 Fields-of-View (FoV) according to [7] with a compound microscope.

Data Analysis: Data collected on cutting experiment were subjected to a one-way Analysis of Variance (ANOVA) and grouping of means using Fisher method at a confidence of $95 \%$. Data on root segment colonization and number of spores counted were analyzed using descriptive statistics with graphs where necessary. Minitab Software version 16 and Microsoft excel were used in data analysis. The model for the cutting experiment is as follows;

$\mathrm{Y}_{\mathrm{ij}}=\mu+\tau_{\mathrm{i}}+\varepsilon_{\mathrm{ij}}$

Where:

$\mathrm{Y}_{\mathrm{ij}}=$ the $(\mathrm{ij})^{\text {th }}$ observation for $\mathrm{i}=1,2,3$ and $4 ; \mathrm{j}=1,2,3$, 4 and 5

$\mu=$ parameter common to all treatments (the mean)

$\tau_{\mathrm{i}}=$ the $\mathrm{i}^{\text {th }}$ treatment effect

$\varepsilon_{\mathrm{ij}}=$ random error component with normal distribution

\section{Results and Discussion}

\subsection{Vegetative Propagation of Khaya Anthoteca}

There was significant effect of the treatments administered on the number of roots from cuttings of six months old seedlings of Khaya anthoteca. However, the length of the longest root was not significantly affected although there were differences among the treatment means. Again, all the cuttings recorded $100 \%$ survival for the duration of the experiment. Analysis of Variance (ANOVA) tested at $\alpha=5 \%$ significance level showed a significant effect of both hormone and wounding effect on the rooting number of Khaya anthoteca cuttings over the control treatment (Table 1). Aside mineral nutrition, hormone and wounding are some of the treatments usually administered to cuttings to hasten root development.

According to [13], treating cuttings with auxins as a plant regulator is purposely to increase the percentage of cuttings that form roots, hasten root initiation as well as increase uniformity of rooting. However, plant whose cuttings root easily may not justify the additional expense and efforts of using these materials. Treatment means of wounding without hormone (T3) was not significantly different from wounding with hormone (T4). Other previous studies have indicated that cuttings derived from juvenile stock plants are easier to root $[1,2,4,6]$. This may be a factor in the observed percentage survival for all the treatments. Similar observations were also made between treatments 1 and 2 (Table 2). This suggests that wounding and growing stage of plant play crucial roles in the rooting of cuttings especially from Khaya anthoteca seedlings as the treatments means were not significantly different.

The superior rooting ability of cuttings from seedlings over that of matured trees in most studies has been attributed to the effect of changes in the woody plant developmental process that occur with increasing age; these are known as maturation or ontogenetic aging. Ontogenetic aging is often found to be most advanced in the upper parts of a tree and least advanced near the base of the trunk, with intermediate conditions between. As tree species possess meristems that are normally perennially dormant and mature more slowly than active ones, these meristems often produce vigorous sprouts (e.g., stump sprouts) after the release of dormancy [5, 11, 12]. The rooting ability of juvenile cuttings has been ascribed to optimum levels of sugars and the total carbohydrate content and low nitrogen [4]

Table 1. One-way ANOVA for Number of Roots (cm)

\begin{tabular}{llllll}
\hline Source & DF & SS & MS & F & P \\
\hline Treatments & 3 & 35.35 & 11.78 & $4.58^{*}$ & 0.017 \\
Error & 16 & 41.20 & 2.58 & & \\
Totals & 19 & 76.55 & & & \\
\hline
\end{tabular}

*significant at $\alpha=5 \%$

The length of the longest root was not significantly affected although there were differences among the treatment means. Auxin transport has naturally been studied almost exclusively in young seedlings, where synthesis takes place in the actively proliferating tissues. From these regions, direction of movement is described as basipetal. Movement in the opposite direction, toward the morphological apex, is referred to as acropetal. However, it more evident that directed auxin transport may be lateral as well as up and down. In roots, there appear to be two transport streams. An acropetal stream, arriving from the shoot, flows through xylem parenchyma cells in the central cylinder of the root and directs auxin toward the root tip. A basipetal stream then reverses the direction of flow, moving auxin away from the root tip, or basipetally, through the outer epidermal and cortical cell files [15]. This up and down flow of hormones may account for the observed indifference among the treatment means for the length of the longest root as the hormones are naturally distributed laterally within the tissues of the plant. Some studies have also reported that wounding a cutting initiates a chemical signal that induces changes in the metabolism of affected cells [23].

Table 2. Grouping of Treatment Means Using Fisher Method at a confidence of 95\%

\begin{tabular}{|c|c|c|c|c|}
\hline \multirow{2}{*}{ Treatments } & \multirow{2}{*}{$\mathrm{N}$} & \multicolumn{2}{|l|}{ Mean \pm SE Mean } & \multirow{2}{*}{ Percentage Survival } \\
\hline & & Number of Roots & Length of Root & \\
\hline $\mathrm{T} 1$ & 5 & $2.20 \pm 0.49^{\mathrm{b}}$ & $8.30 \pm 0.93^{\mathrm{a}}$ & $100 \%$ \\
\hline $\mathrm{T} 2$ & 5 & $3.20 \pm 0.66^{\mathrm{b}}$ & $8.74 \pm 2.30^{\mathrm{a}}$ & $100 \%$ \\
\hline T3 & 5 & $4.20 \pm 0.66^{\mathrm{ab}}$ & $8.70 \pm 2.46^{\mathrm{a}}$ & $100 \%$ \\
\hline $\mathrm{T} 4$ & 5 & $5.80 \pm 0.97^{\mathrm{a}}$ & $13.72 \pm 3.47^{\mathrm{a}}$ & $100 \%$ \\
\hline
\end{tabular}

Means that do not share a letter in the same column are significantly different according to Fisher at a confidence of $95 \%$ 
Wounding the base of stem cuttings can enhance root production [13] and is one of the factors affecting the regeneration of plants from cuttings. In this process, cell division and production of roots primordia are stimulated through wounded tissues. This has been attributed mainly to the natural accumulation of auxins and carbohydrates in the wounded area and in the increase of respiration rate in the creation of a new "sink area". Injured tissues from wounding produce ethylene which may indirectly promote adventitious root formations [13]. The use of stem cuttings, according to [18] has become a common propagation method in forestry and agroforestry. Root initiation in stem cuttings requires that there is an appropriate environment that would reduce post-severance and physiological stress in the cutting [13].

In this study, it is clear that wounding the base of stem cuttings can enhance the number of root production as reported by [13] and as such where hormone is unavailable wounding is adequate for the vegetative propagation of Khaya anthoteca juveniles.

\subsection{Arbuscular Mycorrhizae Fungi (AMF) Root Colonization}

Differences in percentage root segment colonization and mean number of spores between the plant species were analyzed using descriptive statistics and Analysis of variance (ANOVA). ANOVA test revealed no differences at significant level of $\alpha=5 \%(F=2.05, p=0.148$ and $F=2.93$, $\mathrm{p}=0.071)$ in both parameters respectively for the species used for the trapping experiment. After four months of trapping Arbuscular Mycorrhizae Fungi (AMF) from soils under Khaya anthoteca plantation, the roots of Sorghum bicolor were more susceptible to infection compared to Puereria javanica and Khaya anthoteca recording the highest percentage of root segment colonization and the average number of spores per $50 \mathrm{~g}$ of soil of $43 \%$ and 5.1 respectively (Figures 1 and 4).

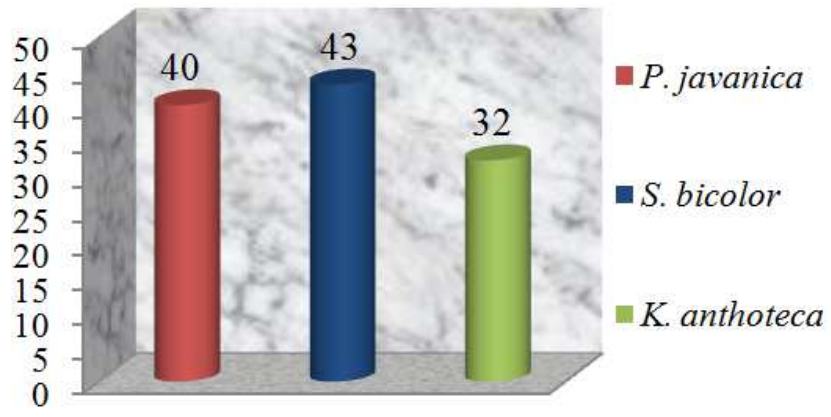

Figure 1. Average percentage of root segment colonization

Traditionally, AMF have been considered to be generalists with regard to the hosts that they infect. They have also been considered to be functionally equivalent in their effects on a host. These have been largely attributed to the fact that most AMF can successfully infect a wide range of plant species in monocultures $[3,8,9,17]$.
Again, most studies have also suggested that some plant species are baits for AMF and therefore more susceptible. Root segment colonization by AM fungi was generally moderate across all species, with few samples below 30\% for Puereria javanica and Khaya anthoteca and a substantial number above $40 \%$ colonization. Colonization was particularly somewhat low to moderate in Khaya anthoteca with no sample below $20 \%$ colonization (Table $3)$. Several hundred fungal species under natural conditions are associated with and colonize plant roots. The preference or specificity for partners in these symbiotic relationships is therefore a key to understanding how the community structures of root-associated fungi and their host plants influence each other in diverse ways [22]. According to [20], mycorrhizal fungi facilitate the soil nutrient acquisition of plants and thereby enhance the competitive ability of their specific hosts in local communities [19].
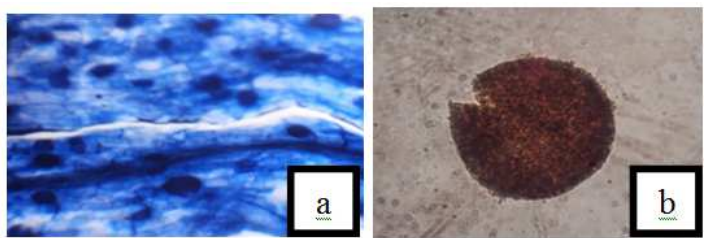

Figure 2. a) Colonization of root segments of Khaya anthoteca b) Isolated single spore of AMF in soil sample

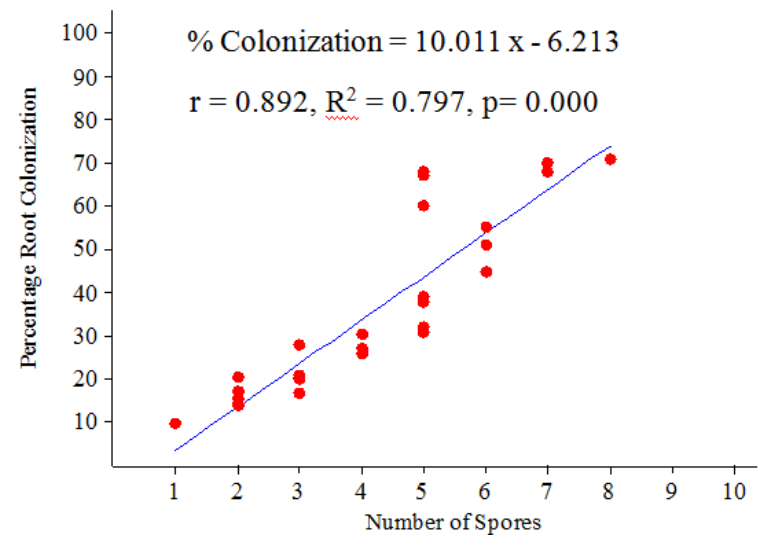

Figure 3. Correlation of percentage root colonization and number of spores per $50 \mathrm{~g}$ of soil.

According to [7], growth substrates, plant and fungal materials, watering, nutrient supply and environmental conditions are some of the major factors that significantly affect the performance of mycorrhizal plants in the glass house. The chemical properties such as the $\mathrm{pH}$ of the soil are of vital importance. Plants grown in glasshouse are typically grown from seeds. This ensures uniformity since it aids in avoiding interference with treatment effects.

Table 3. Average percentage of root segment colonization

\begin{tabular}{lllllllllll}
\hline Sample Species & $\mathbf{1}$ & $\mathbf{2}$ & $\mathbf{3}$ & $\mathbf{4}$ & $\mathbf{5}$ & $\mathbf{6}$ & $\mathbf{7}$ & $\mathbf{8}$ & $\mathbf{9}$ & $\mathbf{1 0}$ \\
\hline P. javanica & 50 & 58 & 57 & 58 & 28 & 20 & 36 & 31 & 30 & 31 \\
Sorghum & 60 & 51 & 41 & 45 & 41 & 37 & 31 & 45 & 35 & 42 \\
K. anthoteca & 36 & 42 & 35 & 40 & 38 & 31 & 25 & 24 & 27 & 26 \\
\hline
\end{tabular}


Khaya anthoteca used in this study were vegetatively propagated in the glasshouse and may be a cause for the observed differences in root colonization as compared with the other species. In this study, Pearson's correlation analysis between the number of spores isolated in the soil samples and the percentage of root segment colonization was very strong with a correlation value (r) of 0.892 (Figure 3). Again, no significant differences were observed among the species with respect to the number of spores per $50 \mathrm{~g}$ of soil

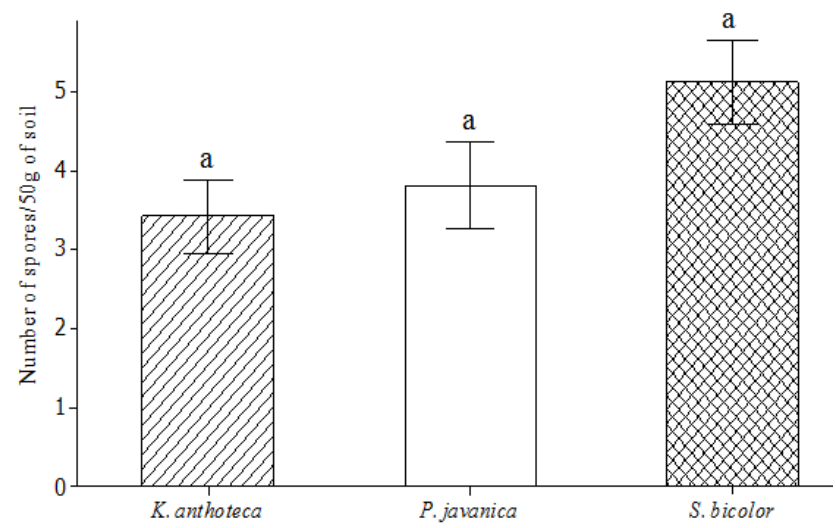

Figure 4. Interval plot of number of spores

In this study, no significant differences were observed among the species in terms of root colonization and average number of spores per $50 \mathrm{~g}$ of soil (Figures 1 and 4) respectively. There is also a positive correlation between the number of spores isolated in the soil samples and the average root segment colonization (Figure 3 ).

\section{Conclusions}

Seeds are the most common way of natural plant regeneration in most species. However, vegetative propagation methods offer several advantages. Furthermore, individuals may be recognized within populations that produce a higher quality of the desired product(s) or services. Vegetative propagation using leafy stem cuttings has been successful in most African mahoganies. In this study, juvenile plants (seedlings) of Khaya anthoteca for vegetative propagation through cutting were significantly affected by both wounding and the application of synthetic hormone. The rooting ability of juvenile cuttings has been ascribed to optimum levels of sugars with high levels of total carbohydrate content and low nitrogen. Again, wounding also initiates a chemical signal that induces changes in the metabolism of affected cells. Juveniles of Khaya anthoteca can therefore be propagated without hormone but with only wounding.

Mycorrhizal fungi have over the years also played critical roles in nutrient cycling and terrestrial ecosystem functioning. In this mutualistic symbiosis, plants exchange photosynthates, not only for mineral nutrients, but also for increased resistance to disease, drought and extreme temperatures. Root segment colonization of $K$. anthoteca cuttings were not significantly different from that of the bait species used in this study namely; $S$. bicolor and $P$. javanica indicating that, $K$. anthoteca is also susceptible to AMF and again, soil inoculums can help contribute to the success of establishing $K$. anthoteca both in the nursery and on the field.

\section{Acknowledgment}

We are forever grateful to God Almighty for His divine guidance, protection and favours throughout this study. Special thanks go the laboratory experts of the Research Center for bioresources and biotechnology, Bogor Agricultural University (IPB) for their encouragements, support and constructive criticisms towards the success of this work.

\section{References}

[1] Amri E, Lyaruu HVM, Nyomora AS, Kanyeka ZL. 2010 Vegetative propagation of African Blackwood (Dalbergia melanoxylon Guill. \& Perr.): effects of age of donor plant, IBA treatment and cutting position on rooting ability of stem cuttings," New Forests. 39: 183-194.

[2] Berhe D, Negash L. 1998. Asexual propagation of Juniperus procera from Ethiopia: a contribution to the conservation of African pencil cedar," Forest Ecology and Management. 112: $179-190$

[3] Bever JD et al. 1996. Host-dependent sporulation and species diversity of arbuscular mycorrhizal fungi in mown grassland. J. Ecol. 84, 71-82

[4] Bhardwaj DR, Mishra VK. 2005 Vegetative propagation of Ulmus villosa: effects of plant growth regulators, collection time, type of donor and position of shoot on adventitious root formation in stem cuttings," New Forests. 29: 105-116.

[5] Bonga JM, von Aderkas P. 1993. Rejuvenation of tissues from mature conifers and its implications for propagation in vitro, [In: Clonal Forestry I, Genetics and Biotechnology, M. R. Ahuja and W. J. Libby, Eds., Springer, Berlin Heidelberg, Germany. Pp. 182-199]

[6] Browne RD, Davidson CG, Steeves TA, Dunstan DI. 1997. Effects of ortet age on adventitious rooting of jack pine (Pinus banksiana) long-shoot cuttings, Canadian Journal of Forest Research. 27: 91-96.

[7] Brundrett M, Bougher N, Dell B, Grove T, Malajczuk N. 1996. Working with Mycorrhizae in Forestry and Agriculture. AClAR Monograph. Pirie Printers, Canberra, Australia Pp 179-185

[8] Douds DD, Millner PD. 1999. Biodiversity of arbuscular mycorrhizal fungi in agroecosystems. Agric. Ecosyst. Environ. 74, 77-93

[9] Eom AH et al. 2000. Host plant species effects on arbuscular mycorrhizal fungal communities in tall grass prairie. Oecologia 122, 435-444 
[10] Gaur A, Adholeya A. 2004. Prospect of arbuscular mycorrhizal fungi in phytoremediation of heavy metal contaminated soils. Curr. Sci., 86: 528.

[11] Greenwood MS, Hutchison KW. 1993. Maturation as a developmental process, in Clonal forestry I, Genetics and Biotechnology, M. R. Ahuja and W. J. Libby, Eds., Springer, Berlin Heidelberg, Germany, pp. 14-33.

[12] Hartmann HT, Kester DE, Davies FT, Geneve RL. 2002. Hartmann and Kester's Plant Propagation: Principles and Practices, 7th edition, Prentice Hall, New Jersey, USA, Pp 300

[13] Hartmann HT, Kester DE, Davies FT, Geneve RL. 1997. Plant propagation; principles and practices. $6^{\text {th }} \mathrm{Ed}$. USA, Prentice-Hall Inc. Pp 298-355

[14] Hawthorne W. 1998. Khaya anthotheca. The IUCN Red List of Threatened Species. Version 2014.3. www.iucnredlist.org. Downloaded on 24 January 2015.

[15] Hopkins GW, Norman Hüner NPA. 2009. Introduction to Plant Physiology. 4th Ed. John Wiley \& Sons, Inc. USA. Pp 338-448.

[16] Jaenicke H, Jan Beniest (ed) 2002. Vegetative Tree Propagation in Agroforestry; Training Guidelines and References. Kul Graphics Ltd, Nairobi, Kenya. Pp 1-4
[17] Kiers ET et al. 2000. Differential effects of tropical arbuscular mycorrhizal fungal inocula on root colonization and tree seedling growth: implications for tropical forest diversity. Ecol. Lett. 3, 106-113

[18] Leakey RRB, Mesen JF, Tchoundjeu Z. 1990. Lowtechnology techniques for the vegetative propagation of tropical trees. Commonwealth Forest Review 69: 247-257

[19] Nara K. 2006. Ectomycorrhizal networks and seedling establishment during early primary succession. New Phytol. 169:169-178.

[20] Smith SE, Read DJ. 2008. Mycorrhizal Symbiosis, 3rd ed. Elsevier and Academic, New York

[21] Smith SE, Read DJ. 1996. Mycorrhizal Symbiosis. Academic Press, San Diego.

[22] Toju H, Sato H, Yamamoto S, Kadowaki K, Tanabe AS, Yazawa S, Nishimura O, Agata K. 2013. A massively parallel pyrosequencing analysis of the association specificity of root-associated fungi and their host plants. Journal of Ecology and Evolution 3: 112-124

[23] Wilson PJ, van Staden J. 1990. Rhizocaline, rooting cofactor and the concept of promoters and inhibitors of adventitious rooting; a review. Annals Botany 66:476-490. 